\title{
Uma substituição luminosa: \\ tributação e reforma do Antigo Regime português em \\ D. Rodrigo de Souza Coutinho ao final do século XVIII
}

Bruno Aidar

Doutorando em História Econômica pela FFLCH/USP

\section{Palauras-chave}

fiscalidade, D. Rodrigo de

Souza Coutinho, reformismo ilustrado, Portugal,

século XVIII.

Classificação JEL B12, B31, N43.

\section{Key words}

fiscality, D. Rodrigo de Soura Coutinho, enlightened reform, Portugal, $18^{\text {th }}$ century.

JEL Classification B12, B31, N43.

\section{Resumo}

A fiscalidade constituiria um dos principais eixos do reformismo ilustrado português ao final do século XVIII. Os escritos do estadista D. Rodrigo de Souza Coutinho (1755-1812) apresentam um conjunto rico das ideias de tributação a estabelecerem novas bases de legitimidade para a extração fiscal do excedente econômico dos vassalos reinóis e americanos pelo soberano português. A partir da influência de novas ideias (o liberalismo econômico smithiano e fisiocrata) e de novas práticas do governo absolutista (a administração ilustrada no Piemonte-Sardenha e na Lombardia austríaca), operarem-se transmutações e metamorfoses ao contexto imperial luso-brasileiro que, longe do mero simulacro, apontavam a singularidade colonial em tempos críticos nos quais os excessos tributários atuaram frequentemente como estopim de revoluções no Velho e no Novo Mundo.

\section{Abstract}

Fiscal issues were central in the Portuguese enlightened reform at the end of the Eighteenth century, especially after revolutions in Western Europe and America that were triggered by tax conflicts. The writings of the Portuguese statesman D. Rodrigo de Souza Coutinho (1755-1812) show a great number of new ideas about taxation, which also belped to create new ways to legitimate the Crown's fiscal extraction of the economic surplus from Portuguese and American vassals. The article defends the position that under the influence of new economic currents (Smith and the Physiocrats' liberalism) and new absolutist government practices (the enligbtened administration in Piedmont-Sardinia and Austrian Lombardy), these fiscal ideas were adapted and transformed, not just copied, to fit the Luso-Brazilian imperial framework. 


\section{1_Introdução}

$\mathrm{Na}$ crítica ilustrada às causas da decadência do reino português, tem-se destacado, entre os pontos comuns aos herdeiros do legado pombalino, a importância da transferência das novas ideias do liberalismo econômico, bem como a relevância da vivência política em cortes estrangeiras, algumas delas lugares pioneiros na reforma do absolutismo. Menos, porém, do que o mero simulacro, a transmutação dessas ideias e a metamorfose de conceitos aplicados alhures constituem um campo rico para a análise das transformações operadas no Antigo Regime português, em tempos de crise. Em especial, a adequação das ideias ilustradas na administração dos domínios americanos mobilizou os interesses dos homens do saber e do poder na construção de novas bases para a monarquia lusitana.

Estopim de revoluções no Velho e no Novo Mundo, os tributos estavam entre as preocupações primeiras dos estadistas ilustrados no último decênio do século XVIII. Desde meados da década de 1760 , as tentativas de arrocho fiscal das 13 colônias na América do Norte, por meio do aumento da influência do Parlamento inglês sobre as assembleias coloniais e pela tributação de produtos importados com o Sugar Act e o Stamp
Act, foram uma motivação central para a emancipação. No vice-reino do Peru, a "grande rebelião" de 1780 foi em parte ocasionada pelo aumento da taxa cobrada nas alcabalas e o estabelecimento de postos alfandegários entre Cuzco e Potosi.

$\mathrm{Na}$ América portuguesa, a cobrança compulsória das dívidas do quinto do ouro foi tradicionalmente associada à Inconfidência Mineira, embora uma análise mais apurada tenha demonstrado os interesses particulares dos contratadores de impostos envolvidos na revolta. No caso da França, a crise financeira da década de 1780, ironicamente agravada pelo endividamento com os gastos da ajuda americana, exigiu reformas fiscais que derrogassem os privilégios da nobreza e do clero; porém, a convocação dos estados gerais foi seguida pelo aumento das demandas do terceiro estado e pela ruptura dos espaços de negociação que sustentavam a monarquia (Bonney, 1996b; Morgan, 1948; O’Phelan, 1986; Maxwell, 1977 e Guéry, 1978).

Com a Revolução Francesa, a situação financeira das monarquias europeias piorou consideravelmente com o crescente aumento das despesas militares para a defesa ou combate à "Grande Nação". No caso dos impérios ibéri- 
Sobre D. Rodrigo de Souza Coutinho, ver: Silva (2002-2006), Silva (2006) e Santos (2006). Sobre os aspectos fiscais do reformismo ilustrado, ver: Costa (2003), Cardoso (2001 e 1989), Maxwell (1999), Novais (1995, p. 213-285) e Lyra (1994, p. 61-81). Sobre a formação das finanças régias em Portugal na época moderna, ver os seguintes trabalhos: Silva (2005), Hespanha (1993) e Godinho (1992). Para uma visão geral das finanças da América portuguesa, ver: Carrara (2009a e 2009b) e Araújo (2008). Por motivos de espaço no texto, não se desenvolveu aqui a crítica de D. Rodrigo aos contratadores de impostos. cos, observa-se enorme dependência dos domínios americanos para fazer frente aos novos gastos em vez de aumentarem a extração de recursos na própria metrópole. A Espanha passou a depender sobretudo de donativos e empréstimos realizados pela Nova Espanha, já sobrecarregada com a sustentação militar do Caribe (Marichal, 1999). Portugal, por sua vez, buscou um caminho que onerasse em menor grau a revitalização econômica do império americano. Neste sentido, os escritos de D. Rodrigo de Souza Coutinho (1755-1812), ao final do século XVIII, permitem realizar a conexão entre os projetos de reforma fiscal e de reforma do sistema colonial tanto na superação das dificuldades financeiras daqueles anos - as premências da conjuntura - como na rearticulação das relações entre metrópole e colônia - o domínio das estruturas.

Tendo em conta o conjunto de textos escritos por Souza Coutinho, o objetivo do presente trabalho é apontar as diversas transmutações e metamorfoses operadas no novo discurso econômico sobre a fiscalidade com base na observação prática dos governos ilustrados no norte da Itália e das leituras de Adam Smith e dos fisiocratas franceses. Embo- ra seja reconhecida de modo geral a influência smithiana sobre os escritos financeiros de Souza Coutinho, apenas José Luís Cardoso a apontou explicitamente na análise da tributação colonial do ilustrado (Cardoso, 2001, p. 84). Contudo, é preciso ponderar outras influências igualmente relevantes, bem como reconstituir a metamorfose dessas ideias e das próprias reflexões de Souza Coutinho desde sua permanência em Turim até a presidência do Erário Régio.

$\mathrm{O}$ artigo busca contribuir para se reduzir tal lacuna nos estudos sobre o estadista, mas evidentemente sem esgotar outras abordagens possíveis. Ademais, observa-se que a despeito de similitudes nas críticas ao peso fiscal sobre a agricultura, havia objetivos distintos na análise de D. Rodrigo quanto aos temas fiscais da metrópole e da colônia. Enquanto no primeiro caso a crítica servia aos intentos de reforma social, notadamente o combate aos traços estamentais da sociedade portuguesa, no segundo caso o foco principal era o crescimento econômico da colônia e a recuperação do império. Após um breve relato biográfico do estadista, tratamos dessas críticas nas seções subsequentes. ${ }^{1}$ 


\section{2_ D. Rodrigo de Souza Coutinho: notas biográficas}

De origem nobre, tendo o pai diplomata e como padrinho de batismo o marquês de Pombal, D. Rodrigo de Souza Coutinho fora educado no Colégio Real dos Nobres e no curso jurídico da Universidade de Coimbra. O êxito nos estudos e uma curiosidade ímpar preparariam D. Rodrigo para a carreira diplomática, a exemplo do pai. Em 1778, seria nomeado "enviado extraordinário" e ministro plenipotenciário na Sardenha. Antes de assumir seu cargo, conheceria Madrid e Paris, cidade na qual travaria contato com os ilustrados franceses, inclusive D'Alembert e o abade Raynal, e estrangeirados portugueses, como o médico Ribeiro Sanches e o duque de Lafões, que no ano seguinte fundaria a Academia Real de Ciências de Lisboa. As principais influências sobre $\mathrm{D}$. Rodrigo seriam D. Luís da Cunha, o marquês de Pombal, e Francisco Ribeiro Santos, médico e humanista português exilado em Paris a maior parte de sua vida.

Em Turim, D. Rodrigo permaneceria por cerca de dezessete anos, entre 1779 e 1796, acompanhando de perto as reformas ilustradas do rei Victor Amadeu III, e mesmo aquelas de traços mais liberais realizadas por José II na Lom- bardia austríaca, enquanto de longe analisava as transformações pelas quais passariam Portugal, Inglaterra e França. Um relógio que se adiantava extraordinariamente, diria tantos anos depois Hipólito da Costa (Lima, 2000, p. 141).

Como embaixador no Piemonte, D. Rodrigo pode completar sua formação intelectual e preparar-se como homem de Estado. Ainda em Turim, as reflexões do ilustrado em muito ultrapassariam suas funções naquela corte, sendo até mesmo motivo de certo ressentimento pela receptividade com a qual seus conselhos eram tomados em terras italianas ao lado da indiferença de seus conterrâneos. Mas, de modo geral, o cosmopolitismo dos estrangeirados presente em D. Rodrigo seguia a linha do iluminismo português do século XVIII na constatação decadentista do atraso do reino ante as potências europeias.

A partir de setembro de 1796, D. Rodrigo seria nomeado para a Secretaria de Estado da Marinha e Domínios Ultramarinos, substituindo o lugar que fora ocupado anteriormente por Martinho de Mello e Castro, morto em março de 1795, permitindo-lhe empreender tentativas de implantação de suas ideias de reforma do reino e do império. Apesar de muitas dessas ideias seguirem uma linha 
2 Sob os embates a respeito das finanças régias, Ponte de Lima e Souza Coutinho expressavam os polos opostos de diferentes grupos políticos da Corte. Os conflitos entre o partido "puritano" e o da "reforma" foram notados por Domingos Vandelli, e o último grupo possuía a clara preferência do italiano: tal partido "amava o soberano, desejava o respeito do trono, queria que houvesse justiça, que não tivesse lugar a dilapidação do patrimônio público. [...] Esse partido lembrava 'reforma', economia nas finanças, aquisição de crédito perdido" (Pedreira e Costa, 2008, p. 84).

3 Ressalva seja feita ao cameralista Johann von Justi (1720-1771), cujos princípios de tributação em muito se assemelhavam aos quatro cânones estabelecidos por Adam Smith (Bonney, 1996a, p. 177-178). de coerência com sua missão em Turim, não deixariam de atentar para os apelos das circunstâncias em moldá-las e reorientá-las no contexto conturbado do combate à Revolução Francesa e, posteriormente, do expansionismo napoleônico. Ainda na secretaria, D. Rodrigo teve conflitos com a jurisdição do Real Erário, então presidido pelo marquês de Ponte de Lima, para a realização de obras na Marinha. ${ }^{2}$ Tal situação aponta a questão importante de que muitas das ideias de império federativo e de liberalização comercial entre os domínios escritas na sua famosa Memória sobre os melhoramentos dos dominios de Sua Majestade na América (1797) só fossem implementadas em realidade a partir de 1801, quando ocuparia o cargo de presidente do Real Erário e ministro e secretário de Estado da Fazenda. Como presidente do Erário Régio, D. Rodrigo conseguiria realizar alguns dos projetos aos quais almejava no cargo anterior quanto à extinção dos contratos do sal e da pesca das baleias, além das reformas da administração das minas de ouro e diamantes (Silva, 1993, v. 1, p. 12-52).

\section{A crítica à fiscalidade na metrópole portuguesa}

No Antigo Regime, a desigualdade da tributação estava principalmente ligada às estratégias fiscalistas do mercantilismo, por um lado, e à sobrevivência de privilégios fiscais decorrentes da posição social, política ou religiosa ou mesmo de privilégios regionais e locais ainda persistentes, por outro. Ainda assim, deve-se ressaltar que, embora as reclamações contra os coletores fossem tão abundantes na Roma antiga quanto na França de Turgot, os privilégios fiscais eram menores do que na Antiguidade. Em 1789, os impostos indiretos eram pagos por todos os franceses. A única exceção eram os impostos diretos, especialmente a talha. As vintenas, a capitação e as gabelas possuíam desigualdades no tratamento, mas não isentavam legalmente os súditos franceses (Fournier de Flaix, 1885, v. 1, p. 13).

Entre as ideias partilhadas da segunda metade do século XVIII, os reformistas passam a ver com maior suspeita os numerosos entraves ao desenvolvimento econômicto, especialmente após a difusão das ideias fisiocratas e liberais. ${ }^{3}$ Os primeiros argumentavam a favor de uma moderação dos impostos sobre a agricultura, base de todo o excedente econômico, enquanto os segundos estendiam menor tributação também para o comércio e as manufaturas.

Em Portugal, o clero mantivera-se praticamente isento do pagamento da si- 
sa, exceto os clérigos comerciantes, e foram sujeitos à décima apenas entre 1672 e 1777 , quando foram temporariamente isentos, medida suspendida em 1796. A enorme importância dos rendimentos eclesiásticos não passou despercebida à crítica das cortes e do pensamento ilustrado do século XVIII presente em D. Luís da Cunha, em Ribeiro Sanches, no marquês de Pombal e em Bacelar Chichorro, além do próprio Souza Coutinho, insistindo-se na igualdade da tributação e alertando-se para o crescente poder econômico da Igreja.

Em parte, a perda dos privilégios eclesiásticos refletia uma vertente do Iluminismo de defesa da secularização. A nobreza, por sua vez, possuía privilégios menores do que o clero: era isenta apenas em impostos locais de pouca relevância para a Coroa, tais como jugadas, quartos e oitavos, mas não nas alfândegas, sisas ou décimas, nas quais era tributada como os não nobres (Hespanha, 1993, p. 207-208). Ribeiro Sanches, por exemplo, criticava a grande quantidade de bens fundiários detidos pelo clero e pela Igreja, bem como o direito à percepção dos dízimos (Serrão, 1988, p. 37). ${ }^{4}$

$\mathrm{Na}$ apresentação das primeiras contas do Tesouro Real, em setembro de 1801, D. Rodrigo, então ministro da
Fazenda, ficaria escandalizado com a desigualdade dos impostos, propondo de maneira geral melhor distribuição do peso fiscal, bem como a supressão de alguns tributos ou sua substituição por outros mais adequados à fortuna de cada um (Silva, 2002-2006, v. 2, p. 180). Decerto, Souza Coutinho contara com predecessores. Para D. Luís da Cunha, por exemplo, era preciso carregar com maiores tributos as terras incultas e taxar com o tributo vigorou nos períodos de 1641-1668, 1704-1715 e após 1762. A jugada era um tributo sobre as terras cultivadas destinado à Coroa e, algumas vezes, a terceiros. Era calculada com base no número de jugos de bois utilizados para se arar a terra. Algumas terras sujeitas à jugaria pagavam o oitavo - a oitava parte - quando a produção de cereal era superior a oito ou mais alqueires. Os dį́imos eram uma contribuição eclesiástica sobre a produção agrícola e pecuária (dízimos reais) e/ou sobre a renda do trabalho (dízimos mistos e pessoais). De origem feudal, foi cobrado pelo rei enquanto grãomestre da Ordem de Cristo após o século XV (Godoy e Medeiros, 1983; Godinho, 1992 e Hespanha, 1993, p. 218).
Com intervalos de suspensão, quando se cobrou apenas $4,5 \%$, 
Recopilação dos ofícios expedidos de Turim, 31 dez. 1783 (Silva, 1993 , v. 1, p. 6-7).

6 Reflexões sobre a fiscalidade e finanças de Portugal (1786) (Silva, 1993 , v. 1, p. 236).

Discurso sobre a mendicidade ([s.d.], 1787 ou 1788) (Silva, 1993, v. 1, p. 221-222). rigor o luxo conforme apontava em suas Instruções (1738) a Marco Antonio de Azevedo Coutinho. No testamento político a D. José I, o velho embaixador fazia referência com acidez aos pais que pediam aos seus filhos que se ordenassem para que não pagassem os impostos devidos, já que os bens seriam incluídos entre os da Igreja, e dizia que era justo que todos concorressem para todas as despesas do Estado, sem gozar de isenção (Cunha, 1976, p. 71).

Em 1777, Sebastião José de Carvalho e Mello indicava como fonte de recurso, a ser utilizado para os lavradores em seus "avances”, a tributação sobre os fidalgos, os eclesiásticos e os cidadãos, "apesar da lei, apesar dos Privilégios, apesar dos Decretos do Soberano”. Não é preciso aqui retomar a violenta contenda entre o marquês de Pombal e o clero: as críticas à ociosidade e à inutilidade dos seus membros, a grande quantidade de terras das ordens a crescer ainda pelas doações e aquisições, os privilégios fiscais da Igreja (Falcon, 1993, p. 253, 275 e 407-409). Da Igreja, Pombal recolheria sob a teia fiscal as capelas vacantes, os resíduos das capelas e os prazos das corporações religiosas, além do confisco dos bens da Companhia de Jesus (Carnaxide, 1979, p. 84-86 e 103).
Em 1783, D. Rodrigo considerava que não havia nada mais desvantajoso ao Estado como a desigualdade da imposição sobre pessoas e bens, recomendando que os encargos de todos os proprietários fossem igualados. ${ }^{5}$ Souza Coutinho aplaudia a decisão de Victor Amadeu II de submeter os bens eclesiásticos a um novo cadastro bem afinado com a igualdade impositiva, mas também era louvável a medida de tributar as carruagens para assegurar os reparos das ruas de Turim, após o inverno (Silva, 2002-2006, v. 1, p. 122).

Ainda em terras italianas, D. Rodrigo consideraria, três anos mais tarde, que os impostos em Portugal eram muito pesados aos povos, e, se fossem moderados, aumentar-se-ia a arrecadação, talvez até dobrasse suas rendas e seria mais útil ao soberano. ${ }^{6}$ Buscava-se, assim, uma solução de compromisso entre os interesses dos vassalos e aqueles do monarca.

As considerações humanitárias relativas à tributação não parecem ter sido ausentes das reflexões de D. Rodrigo. Ao final da década de 1780, afirmava que o imposto ou a sua arrecadação produzia a mendicidade pela desigualdade com que afetava as diversas classes, no primeiro caso, e pela necessidade de empregados e guardas, no segundo. ${ }^{7}$ Ao lado 
da desigualdade, a incerteza na tributação era um mal que deveria ser afastado, sobretudo por meio de impostos que recaíssem sobre o luxo e sobre os estratos mais ricos da sociedade, ao contrário do que ocorrera na França, com "terríveis consequências", e mantivera-se em Portugal. $^{8}$

É a partir do enquadramento geral reformista relacionado ao fomento da agricultura, pela moderação dos tributos, e à crítica dos contratadores que se deve compreender as considerações de D. Rodrigo de Souza Coutinho a respeito dos dízimos. O programa reformista na agricultura apoiava-se principalmente na redução dos impedimentos fiscais que oneravam a produção. Além das sugestões de construir as estradas para comunicação interna, dos canais de navegação e de rega, de utilizar o estrume como adubo e de abolir dos foros e dos morgados, havia a necessidade de diminuir o dízimo

que sendo proporcional ao produto em bruto, e não à renda, é um imposto que, nem as nossas terras, nem as de nenbum outro país, podem sofrer.?

Só assim, dizia, a arruinada agricultura portuguesa poderia adotar as luzes das nações europeias mais iluminadas.
Além disso, nem o dízimo, nem as jugadas faziam mais parte da renda do soberano e "vexam a agricultura sem proveito do Estado". Se fossem substituídas por um imposto territorial único, ${ }^{10}$ um sétimo ou oitavo da renda líquida dos proprietários, tiraria o soberano maior renda, os particulares pagariam muito menos e combater-se-iam as diferenças entre membros extremamente ricos e outros pobres dentro da Igreja. ${ }^{11}$ Conforme afirmava ao final do Setecentos ao príncipe regente:

Ninguém melhor que Sua Alteza Real conhece que a organização de um imposto territorial fixo e produtivo lançado sobre um exato cadastro, que a fixação ao menos por longas épocas dos dízimos eclesiásticos, que os longos arrendamentos, que caixas de crédito a favor dos agricultores, que canais de navegação e rega e outros objetos de tal natureza são os grandes meios de promover e elevar ao sumo ange a agricultura. ${ }^{12}$

A despeito do pequeno número de tributos entre os portugueses quando comparados ao restante da Europa, o peso desses impostos era bastante elevado, desestimulando a prosperidade da agricultura, afirma o ilustrado em 1784:

Se as terras pagassem só a décima da renda livre ao soberano, este tributo seria o mais doce possivel: mas como as terras pagam ao mesmo tempo as jugadas de que o soberano
Reflexões sobre o estabelecimento do crédito público, melboramento da Fazenda Real, e outros objetos..., 29 out. 1795 (Silva, 1993, v. 1, p. 288).

9 Recopilação dos ofícios expedidos de Turim, 3 jan. 1787 (Silva, 1993, v. 1, p. 57-58). Como nota Andrée Mansuy Diniz Silva, as primeiras observações de D. Rodrigo a respeito do peso do fisco sobre a agricultura pertencem não somente aos interesses de Estado, mas também ao terreno privado, uma vez que o embaixador era também, a exemplo de outros nobres, proprietário de quintas em Portugal (Silva, 2002-2006,

v. 1, p. 117).

10 Em 1735, Ribeiro Sanches já defendia a existência de um imposto universal sobre o valor da terra visando ao financiamento de obras públicas e particulares agrícolas (Serrão, 1988, p. 33).

11 Reflexões sobre a fiscalidade e finanças de Portugal (1786) (Silva, 1993, v. 1, p. 234).

12 Discurso feito pelo Il. ${ }^{\text {mo }}$ e Ex. ${ }^{\text {mo }}$ Sr. D. Rodrigo de Soura Coutinho, na abertura da Sociedade Real Maritima, 22 dez. 1798 (Silva, 1993, v. 2, p. 187). 
não colhe fruto algum, pois são dadas a particulares, e os dírimos, que em Portugal se percebem mais fortemente que em nenhuma outra parte, e que vêm a ser realmente a quarta ou quinta parte da renda, segue-se naturalmente que somando estes três impostos o peso chega a ser tão forte que a agricultura não pode prosperar. ${ }^{13}$

Não apenas a agricultura era prejudicada, como também a indústria da seda, que pagava o dízimo sobre os casulos, acrescentava D. Rodrigo em 1789. ${ }^{14}$ Os nocivos dízimos, dizia, não deriva-

\footnotetext{
13 Reflexóes politicas sobre os meios de estabelecer em Portugal a cultura e manufatura da seda, 20 mar. 1784 (Silva, 1993, v. 1, p. 126).

14 Reflexões politicas sobre os motivos da prosperidade da agricultura deste país [Piemonte], que servem a fazer ver praticamente as vantajosas conseqüências dos sábios princípios adotados (1789), (Silva, 1993 , v. 1, p. 147).

15 Discurso sobre a mendicidade ([s.d], 1787 ou 1788) (Silva, 1993, v. 1, p. 219).

16 Relação política da Casa de Sabóia, dez. 1791 (Silva, 1993, v. 1, p. 326). Em 1698, o desembargador Diogo Marchãa Temudo pedia o alívio do peso dos tributos foraleiros sobre os lavradores. A mesma crítica foi realizada
}

pelo desembargador e

chanceler da Casa da

Suplicação José Vaz de

Carvalho em 1749. A despeito

da ausência de um discurso

pombalino unificado sobre

a reforma agrícola no reino,

houve melhorias fiscais para os

lavradores com o congelamento

ou redução das rendas e

prestações foreiras e censíticas

(leis de 16 jan. 1773 e de

4 fev. 1773) (Serrão, 1988,

p. 31,36 e 46$)$.

17 Memória sobre o melhoramento dos domínios de Sua Majestade na América (1797) (Silva, 1993, v. 1, p. 55). Embora a data deste documento ainda seja incerta, 1797 ou 1798, é mais provável que tenha sido escrito em 1797 , data que aqui se adotou. vam de nenhum direito divino, devendo ser abolidos e substituídos por equivalentes, aos particulares que perdessem aquelas comendas. ${ }^{15}$ Essas propostas eram em boa parte refletidas à luz da experiência da Sabóia, cuja limitada extensão dos dízimos, ao contrário de Portugal e da Espanha, estava entre as medidas do governo visando à retirada dos gravames feudais à agricultura, o que incluía também a abolição dos foros e laudêmios. ${ }^{16}$

Como dizia Souza Coutinho, " natureza da taxação depende das origens da riqueza da sociedade". A economia política, ao investigar as bases das riquezas das nações (a renda da terra, os salários e a os lucros do capital), adentrava em uma nova concepção sobre a forma de tributar, pois agora a "boa taxação" significava

distribuir proporcionalmente por estas primeiras fontes da riqueza universal o gravame dos impostos, em maneira tal que sobre todos pese igualmente. ${ }^{17}$

Em uma frase, desdobrava-se uma crítica do Antigo Regime, no qual as desigualdades fiscais decorriam dos privilégios, e as propostas para a sua reforma, a beneficiar as classes produtivas, do ponto de vista econômico, e defensora da igualdade, do ponto de vista político. $\mathrm{Na}$ prática, a feitura e reforma dos impostos deveriam seguir uma série de princípios: 
[... $1^{a}$ a de que o imposto seja tal que cada um contribua em razão de suas faculdades; $2^{a}$ a de que se cobre quando grava menos o que o há de pagar; $3^{a}$ que não seja arbitrário, mas certo; $4^{a}$ que se cobre com facilidade, e que seja tal que se sacrifique para a sua arrecadação o menos que for possivel; $5^{a}$ que não recaia em tal modo sobre uma das fontes de riqueza, que esta venha a ser sacrificada às outras, e que dai resulta ao Estado o mal de se perder todo o sistema do equilíbrio político. ${ }^{18}$

Nenhuma dessas ideias eram-lhe originais, já que representam as máximas da tributação apresentadas por Adam Smith. Com relação às fontes de renda (renda, lucro e salários), Smith considerava que: "Todos os impostos devem finalmente ser pagos de uma ou outra dessas três diferentes espécies de rédito, ou de todas indiferentemente". Os princípios apontados por Souza Coutinho são praticamente os mesmos descritos pelo escocês:

I. Os súditos de todos os Estados devem contribuir para a manutenção do governo, tanto quanto possivel, em proporção das respectivas capacidades, isto é, em proporção do rédito que respectivamente usufruem sob a proteção do Estado. [...] II. O imposto que todo o individuo é obrigado a pagar deve ser certo e não arbitrário. [...] III. Todo o imposto deve ser lançado no tempo ou modo mais provável de ser conveniente para o contribuinte o pagar. [...] IV. Todo o imposto deve ser arquitetado tão bem que tire o minimo possivel do bolso das pessoas para além do que trazpara o erário público (Smith, 1983, v. 2, p. 485-487).

\section{4_ A tributação na nova relação colonial}

É inegável que Souza Coutinho era um profundo conhecedor de Smith entre os autores portugueses, especialmente de suas ideias não apenas com relação à tributação, mas também sobre temas referentes à dívida pública, aos bancos e à circulação fiduciária (Cardoso, 1988, p. 93). A originalidade do ilustrado português, porém, não estava decerto nessas ideias gerais, senão na aplicação ao contexto específico do reino português, particularmente na reforma dos domínios ultramarinos. ${ }^{19}$ Ao avaliar seu governo na Secretaria da Marinha e dos Domínios Ultramarinos, no período de 1796 a 1801, D. Rodrigo apontava a seu sucessor, o visconde de Anadia, o aumento das culturas agrícolas, o melhoramento das rendas reais e a sistematização da administração como o conteúdo principal das ordens expedidas para os domínios coloniais. $^{20}$
18 Memória sobre o melhoramento... (Silva, 1993, v. 1, p. 55).

${ }^{19}$ Contudo, a crítica ao peso excessiva da tributação metropolitana sobre a colônia não seria exclusividade de Souza Coutinho, visto que anteriormente Turgot, Raynal e Campomanes já haviam realizado tal crítica para os casos francês e espanhol (Cardoso, 2001, p. 70-72).

${ }^{20}$ Carta dirigida por D. Rodrigo de Soura Coutinho ao visconde de Anadia quando the entregou a Secretaria de Estado dos Negócios da Marinha e Domínios do Ultramar, 14 jul. 1801 (Silva, 1993, v. 2, p. 25). 
${ }^{21}$ Conforme aponta Richard Bonney: "Ainsi, l'administration des finances aurait à garantir que des fortunes en monnaie ne seraient pas créées, qui retiraient des revenus de la circulation; les impôts ne devraient pas être destructeurs on disproportionnés par rapport au revenu de la nation; ils devraient également être levés sur le produit net de la propriété foncière et non pas sur sa production, ce qui ne servirait qu'à augmenter le coût de la collecte" (Bonney, 1996a, p. 188). Em Mirabeau, por exemplo: 'L'imposition ne devrait pas éteindre la reproduction des revenus': les impôts ne devraient pas se révéler autodestructeurs en éliminant la source des revenus qu'ils cherchaient à taxer" (Bonney, 1996a, p. 191).
A reforma do fisco colonial, tornando-o mais branda, todavia mais eficaz, abarcava justamente esses três campos de atuação do estadista. Ainda assim, a melhoria da tributação colonial percorreria caminhos por vezes contraditórios. De um lado, encontravam-se as agruras das próprias finanças do Estado português ao final do século XVIII. O aumento do montante fiscal arrecadado nos domínios ultramarinos era parte de uma estratégia global de reorganização fazendária, ou seja, estava ligada à própria dinâmica econômica do Estado. Por outro lado, uma tributação mais suave vinculava-se ao programa reformista de diversificação agrícola ao lado do aprimoramento das técnicas e da busca de outras culturas conforme o novo projeto de colonização.

A desigualdade dos tributos que vexavam os súditos americanos da "nação portuguesa" já havia sido destacada por Antonio Rodrigues da Costa, ministro do Conselho Ultramarino, em 1727. Também destacava o conselheiro a pouca necessidade de se cobrar mais tributos e a prolongada duração da contribuição ao dote para o casamento real (Figueiredo, 2005, p. 25-28). Contudo, se nas primeiras décadas do século XVIII as recomendações críticas apoiam-se na teologia moral escolástica, ao final do Setecentos os critérios de julgamento baseiam-se cada vez mais no domínio da nova ideologia secular da economia política.

Nos escritos de D. Rodrigo a relação íntima entre a melhoria das finanças régias e o desenvolvimento da agricultura colonial era testemunha das novas concepções liberais e fisiocratas que minoravam a sanha fiscal do regime mercantilista. Ganhava corpo a ideia de que o Estado arrecadaria mais se fomentasse a economia dos vassalos, pois, se destruísse as bases desta última, certamente teria uma receita fiscal menor. Para os fisiocratas, a tributação não deveria afetar o capital dos proprietários de terras, base da riqueza futura da nação, ${ }^{21}$ argumento depois estendido ao capital das manufaturas e ao trabalho, conforme a formulação de Adam Smith. O soberano teria maiores ganhos de uma forma indireta, estimulando o crescimento das fontes de riquezas das nações, em vez de prejudicá-las com uma tributação punitiva, que, apesar de gerar ganhos fiscais momentâneos, não formava as bases para o crescimento combinado da economia do Estado e a dos seus súditos. Por outro lado, a tributação sobre a riqueza improdutiva era o reverso do projeto reformista, uma vez que D. Rodrigo não deixava de apontar a necessidade de se tributar os 
escravos de luxo, não empregados na lavoura e que serviam de criados nas casas brasileiras. ${ }^{22}$ Isso apenas evidencia a conexão entre fomento econômico e fiscalidade buscada pelo ilustrado português e inspirada pelas novas doutrinas econômicas.

Dentro da estratégia de aumento do montante fiscal arrecadado nos domínios ultramarinos, vemos, por exemplo, as primeiras referências do ilustrado português à reforma da fiscalidade colonial. Em 1795, ainda em Turim, D. Rodrigo afirmava que o restabelecimento do crédito público e o pagamento das despesas requeriam a busca de recursos,

sobretudo se ao mesmo tempo se tentasse o estabelecimento em todas as nossas colônias de uma imposição mais produtiva, e de uma arrecadação mais econômica. ${ }^{23}$

No ano seguinte, já de volta a Portugal e ocupando o cargo de secretário de Estado dos Negócios da Marinha e dos Domínios Ultramarinos, D. Rodrigo apontava em um ofício ao capitão-general de São Paulo à época, Bernardo José de Lorena, uma súmula do programa reformista para a Fazenda colonial que pouco onerasse a produção do ultramar. Ao que tudo indica, logo ao tomar posse do cargo, Souza Coutinho já dispunha de visão clara e madura, com influência li- beral e fisiocrata, que seria explicitada posteriormente na famosa Memória sobre o melhoramento dos domínios de Sua Majestade na América:

Tem merecido na real presença particular atenção, o sistema de introduzir em todos os seus estados da América, um melhor sistema de taxação segundo os luminosos principios, que a experiência tem demonstrado verdadeiros, e que sendo mais produtivos, vem realmente a ser menos gravosos aos povos, visto não impedirem aquela producão, $e$ acumulação de cabedais, e ativa circulação, de que resulta a riqueza dos povos, e por este motivo propõe-se Sua Majestade de introduzir o uso do papel selado, para os contratos, testamentos e outros atos judiciais, como suplemento do que possa puder, abaixando os direitos do sal, e estabelecendo a sua livre circulação. Também Sua Majestade desejava que se taxassem a aguardente e outras bebidas fortes, para aliviar alguma coisa a taxa que se paga nas alfândegas, $e$ por conseqüência, ordena a Vossa Senhoria que remeta todas as informações que puder, sobre a quantidade, e qualidade dos licores que consomem esses povos (Arquivo do Estado de São Paulo, 1924, v. 45, p. 491).

Ao mesmo tempo, não se pode dizer que $\mathrm{D}$. Rodrigo pensasse somente em aumentar a produção da colônia, uma vez que a reformulação das finanças acabava ressaltando a importância
22 Carta para o marquês mordomomor relativa à avaliação das rendas reais e despesas para o ano próximo futuro, 16 fev. 1799 (Silva, 1993, v. 2, p. 128).

23 Reflexões sobre o estabelecimento do crédito público, melhoramento da Fazenda Real, e outros objetos..., 29 out. 1795 (Silva, 1993, v. 1, p. 290). 
${ }^{24}$ Carta para o marquês mordomomor relativa à avaliação das rendas reais e despesas para o ano próximo futuro, 16 fev. 1799 (Silva, 1993, v. 2 , p. 129).

${ }^{25}$ Carta para o marquês mordomomor... (Silva, 1993, v. 2, p. 127). crescente dos domínios ultramarinos para a sobrevivência do reino, denotando a preponderância do projeto imperial sobre um que se dispusesse a encetar reformas profundas na fiscalidade metropolitana. Quando Souza Coutinho pensava na melhoria das finanças régias, associava-a ao projeto de um império reformado. Em seus sonhos mais altos, as cifras que os domínios poderiam render ao soberano não eram desprezíveis.

Em 1799, com base nas projeções de D. Rodrigo, considerando todas as medidas tributárias e de crédito no reino e no ultramar que poderiam render 25 milhões de cruzados ao Estado português, a colônia seria responsável por cerca de 10 milhões, ou seja, 40\% da receita esperada pelos monopólios sobre o tabaco (3 milhões), diamantes e pau-brasil (menos de 4 milhões), direitos de importação e exportação do reino e do Brasil (2,1 milhões), a moeda provincial em Minas Gerais (600 mil) e os novos impostos no Brasil (300 mil)..$^{24}$

As contas de D. Rodrigo misturam rendas da metrópole e do ultramar, mesmo assim é plausível que as receitas coloniais representassem por volta de $30 \%$ do total estimado. Era principalmente pela via tributária que se buscavam essas rendas, visto que o antigo método dos donativos deveria ser descartado conforme a crítica do ilustrado à proposta do tesoureiro-mor de que os governadores do Brasil expedissem cartas régias procurando donativos, pois

\section{o procurar taxar com a moderação devida, e como for necessário o Brasil para servir de base aos empréstimos que lá se mandaram abrir, parece-me muito justo, e até indispen- sável como há muito o propus. ${ }^{25}$}

A distinção entre os tributos a serem aplicados nas capitanias marítimas e aqueles referentes às capitanias mineradoras é de especial interesse para se observar as diferenças da gestão fiscal da América portuguesa. Nos primeiros, os malefícios apresentavam-se no estanco do sal, no contrabando das alfândegas, nos direitos pagos sobre os escravos entrados no Brasil e nos direitos sobre o aço, o ferro, o cobre e o chumbo. O estanco do sal vexava toda a América, sobretudo a criação do gado e a salga das carnes, além de diminuir o montante que poderia ser exportado de Portugal caso o preço fosse mais baixo (Ellis, 1955).

Quanto às alfândegas, o valor excessivo tributado alimentava o contrabando. Se os direitos de alfândega fossem reduzidos, aumentar-se-ia o comércio de vinhos, de azeite, de manufaturados, de 
aço e de ferro do Reino para os domínios de ultramar. Assim, contra a elevação dos tributos, D. Rodrigo pregava o aumento do comércio para dessa forma, mais eficaz, obter um acréscimo do montante arrecadado pelo Estado português. Os direitos sobre os escravos apenas diminuíam a produção dos colonos visto que "impedem o aumento dos bracos $e$ instrumentos que devem cultivar e fazer produtivo o terreno", destruindo, assim, as bases da riqueza. Se fossem substituídos por um pequeno direito de entrada, fomentariam o cultivo. ${ }^{26}$

Além de pregar a supressão ou a redução desses impostos, Souza Coutinho defendia o estabelecimento de impostos mais produtivos e menos onerosos, visto não atingirem as fontes $\mathrm{da}$ riqueza como os anteriores: o imposto do papel selado, um imposto sobre as casas (equivalente à décima urbana do Reino), uma taxa moderada sobre lojas, tavernas, casas de bebidas e casas de pasto, uma taxa moderada de um quarto de oitava sobre cada escravo, um imposto sobre as cartas conduzidas pelos correios marítimos, o estabelecimento de uma loteria anual e, por fim, a introdução de um novo sistema de arrecadação, substituindo a arrematação por contratos, conforme vimos na seção anterior.
Segundo Souza Coutinho, com as modificações propostas, lucrariam tanto a Fazenda Real quanto os colonos:

\section{Parece indubitável que [...] a Faz̨enda Real} ganharia consideravelmente, e que os habitantes ganhariam, pois que as producões vindo a ser taxadas indiretamente, e não se gravando na sua origem, cresceriam em sua totalidade, de que resultaria o aumento das mesmas e da riqueza geral. ${ }^{27}$

Para as capitanias mineradoras, ou seja, Minas Gerais, Goiás, Cuiabá e Mato Grosso, o ilustrado preconizava em parte medidas semelhantes às das capitanias marítimas, tais como a abolição do estanco do sal, especialmente gravosa para as Minas Gerais, e a crítica aos direitos de entrada sobre os negros, ferro, aço, cobre, chumbo, pólvora, azeite, trigo e vinhos do Reino por diminuírem o trabalho das minas.

Por outro lado, algumas medidas eram nitidamente veiculadas para o fomento das regiões de pedras e metais preciosos. Assim, o quinto do ouro deveria ser diminuído para um décimo, "para animar mais os mineiros a novas e úteis tentativas", como fizera a Espanha com suas minas de ouro e de prata ao reduzir para um décimo e depois a um vigésimo o tributo inicial. ${ }^{28}$ Também aconselhava a proibição do curso do ouro em
26 Memória sobre o melhoramento dos dominios de Sua Majestade na América (1797) (Silva, 1993, v. 2, p. 56-57).

${ }^{27}$ Memória sobre o melhoramento... (Silva, 1993, v. 2, p. 58).

${ }^{28}$ Neste ponto, D. Rodrigo avançava com relação aos aspectos fiscais do mercantilismo ilustrado de Pombal, muito embora o alvará de 1750 contivesse elementos progressistas, pois, conforme aponta Luciano Raposo Figueiredo, a derrama ao substituir a capitação incidia sobre todos os grupos sociais (em vez de onerar apenas os mineradores) e exigia um estreitamento dos interesses do rei e dos colonos no combate ao contrabando. A tributação ilustrada deveria "alcançar a todos com igualdade e proporcionalidade à riqueza de cada um" (Figueiredo, 2005, p. 36).

Para uma síntese a respeito do quinto do ouro, especialmente em Minas Gerais, ver Renger (2006). 
${ }_{29}$ Memória sobre o melhoramento dos domínios de Sua Majestade na América (1797) (Silva, 1993, v. 2 , p. 59$)$.

30 Representação ao príncipe regente sobre o alvará para a abolição dos contratos do sal e da pescaria da baleia, 6 ago. 1798 (Silva, 1993, v. 2 , p. 69$)$. pó nas Minas e o estabelecimento de casas de permuta e de casas de moeda. $\mathrm{O}$ distrito diamantino também necessitava de certas medidas, entre elas fixar uma taxa anual para cada escravo que passasse ao local. A substituição por impostos mais produtivos e menos onerosos seguia a mesma linha das capitanias marítimas, com a única diferença da capitação anual de meia oitava sobre cada escravo que entrasse no distrito diamantino e de um vigésimo de oitava para cada escravo válido ocupado nas lavras de ouro.

Com relação à diversificação agrícola, a crítica recaía sobre os dizimeiros e sobre os estancos. O problema dos dízimos não era apenas o peso sobre a agricultura, mas sobretudo o fato de que, do montante arrecadado, pouco chegasse às mãos régias, ainda mais quando serviam ao enriquecimento dos dizimeiros e ao dos membros do clero, no esteio da crítica secular do Iluminismo no Setecentos. D. Rodrigo preconizava que a cobrança dos dízimos deixasse de ser feita pelos contratadores e passasse a ser realizada por administrações reais que fixariam o valor do tributo por certo número de anos. Assim, seria benéfica tanto à $\mathrm{Fa}$ zenda Real quanto ao lavrador, "que cessaria de ser vítima de vexações e de requisições arbitrárias" perpetradas pelos dizimeiros. ${ }^{29}$
No que concerne aos estancos, o exemplo mais conspícuo é justamente do projeto de alvará para abolição dos contratos de sal e da pesca da baleia. Somente a partir de 1801, D. Rodrigo conseguiria implementar, durante sua gestão no Erário Régio, ideias formuladas anos antes. $\mathrm{Na}$ base desse projeto, encontra-se a intenção de substituir antigos impostos por outros "mais razoáveis e mais produtivos", a diminuição dos direitos sobre o vinho português e sobre o ferro, ouro e diamantes, que fomentaria sua extração nas minas de São Paulo, Angola e Minas Gerais. Como dizia D. Rodrigo, a tributação sobre o metal nobre e as pedras preciosas era tão elevada que poderia tornar sua produção insignificante, e o contrabando cada vez mais recorrente. ${ }^{30}$ Era justamente este o ponto em que se batia o estadista: a imposição excessiva poderia levar à ausência do que se pudesse tributar, posto que a produção dessas riquezas fosse tão onerosa que conduzisse ao seu abandono pelos colonos.

D. Rodrigo não deixava de espelhar as considerações de Adam Smith sobre a decadência das minas espanholas, dado que ao governo castelhano cabia metade do ouro e da prata descobertos, tornando o tributo insuportável e 
levando ao abandono das minas, o que foi solucionado pela redução da imposição (Smith, 1983, v. 2, p. 99). Aplicada à situação portuguesa, também a Coroa nem atingia seu propósito de aumentar as rendas reais, nem estimulava a produção e desenvolvimento da colônia. Era preciso encontrar aquele justo equilíbrio entre o fisco e a riqueza dos vassalos americanos, já que deixar de fazê-lo seria ruína do Erário e perigo de sublevação, pondo em risco as relações econômicas e políticas entre a metrópole e os seus domínios.

Assim, D. Rodrigo criticava aquelas medidas da administração colonial que feriam as fontes de riqueza colonial, oprimindo os produtores e desestimulando a agricultura. As autoridades coloniais não deveriam expedir ordens que obrigassem os lavradores a darem escravos, gêneros e carros sem necessidade, ou quando isso fosse indispensável deveriam ser pagos rapidamente, os gêneros a preços correntes, para que não prejudicassem "seus tão úteis trabalbos [...] pois que assim se animam as plantaçöes, e se não prejudica ao povo." 31

Para a agricultura ilustrada, as melhorias fiscais estavam ao lado das técnicas. Em instruções para o intendente geral das minas na capitania de Minas
Gerais e Serro Frio, o estadista português pede tanto uma relação da

imposição que paga essa capitania, sobre - peso de que poderá ser aos proprietários $e$ às culturas, sobre a sua proporção com o produto do terreno, em que recai, sobre os meios de a fazer mais produtiva e menos onerosa por meio de alguma substituição $e$ alteração luminosa

quanto dos melhoramentos que poderiam ser introduzidos para benefício das culturas, melhores métodos de trabalhar e adubar o terreno e melhoramentos em máquinas e fornos do açúcar e outros gêneros. ${ }^{32}$

Também nesse ponto refletia as considerações de Smith, uma vez que esse prezava, como fatores de prosperidade das colônias inglesas na América do Norte, cujo progresso havia sido o mais rápido entre as colônias, certas características na posse de terras, no monopólio comercial menos opressivo e na moderação dos impostos cobrados pela metrópole. Este último fator permitia aos colonos não apenas aumentarem sua produção tanto em volume quanto em valor, como também reinvestirem boa parte da sua produção, expandindo-a:

Em conseqüência da moderação dos seus impostos, uma grande parte dessa produção pertence-lhes, podendo eles armazená-la e
${ }_{31}$ Aviso e instruçôes para $D$. Fernando José de Portugal, governador e capitão general da Capitania da Babia, $1^{\circ}$ out. 1798 (Silva, 1993, v. 2, p. 42).

32 Instrucõos para Manuel Ferreira da Câmara, intendente geral das minas na capitania de Minas Gerais e Serro Frio, 26 nov. 1800 (Silva, 1993, v. 2, p. 74-75, grifos meus). 


\footnotetext{
Soura Coutinho feito na Sociedade Real Maritima, Militar e Geográfica, 7 jan. 1800 (Silva, 1993, v. 2, p. 191).
}

utilizá-la na movimentação de ainda mais trabalho (Smith, 1983, v. 2, p. 117).

Ao lado das propostas de criação de bancos, da melhoria técnica da extração aurífera, do incremento das técnicas agrícolas, a inserção de ideias liberais e fisiocratas aplicadas ao contexto colonial passava com igual importância pela transformação fiscal "mais doce e mais produtiva" a ponto de afigurar no soberbo discurso de D. Rodrigo na Sociedade Real Maritima, Militar e Geográfica, por ele criada, ao início do século XIX, quando se podiam ver aquelas primeiras mudanças que suas reformas haviam desencadeado:

Aqui desejara en que me fosse possivel, com atrevida mas fiel mão, erguer o véu que deve cobrir muitas providências, dadas por Sua Alteza Real, que já principiam a executarse, mas ainda não inteiramente realizadas, tais as de uma taxação mais doce e mais produtiva em todas as capitanias do Brasil, quais as da criação de caixas de crédito e circulação para animar e sustentar as produções do Brasil em qualquer abalo que possam ter os mercados da Europa; e quais finalmente as que ainda se discutem a favor das nossas ricas minas, fundadas sobre os princípios mais sólidos, os mais luminosos, $e$ os mais liberais, se é lícito adotar na nossa lingua esta palavra no sentido que os ingleses the atribuem. ${ }^{33}$

\section{5_Considerações finais}

Documento clássico para o estudo do reformismo ilustrado, a Memória sobre o melhoramento dos dominios de Sua Majestade na América, de Souza Coutinho, teve a maior parte do seu conteúdo - justamente a proposta de reforma fiscal - pouco explorada pelos historiadores do período tanto com relação às ligações com a própria trajetória do estadista quanto perante o quadro europeu de circulação de novas ideias econômicas. Ademais, o enquadramento dessa fonte permite colocar em perspectiva a unidade e a plasticidade das ideias reformistas em Portugal, ao final do Setecentos.

Não há decerto um único plano fiscal para ser aplicado no reino e nos domínios ultramarinos, como se buscou apresentar no presente texto, mas é possível perceber as sucessivas adaptações e distorções de um grande conjunto teórico, provido particularmente por Smith, e empírico, a experiência dos reinos italianos, que oferecia, conforme se acreditava, a possibilidade de superar os obstáculos do Antigo Regime português dentro da ordem, sob a égide do crescimento econômico dos súditos e do Estado.

Por outro lado, se o receituário fiscal de D. Rodrigo aparece como forma de superar contradições de sua época, 
não deixa de ser evidente que a crise vai se manifestar em outro plano, justamente na distância entre a teoria e a prática dessas políticas econômicas em Portugal e na América. Síntese da "desordenada ilustração", no dizer de Oliveira Lima, Souza Coutinho era a própria personificação da enorme capacidade e dos inúmeros desafios da geração reformista de 1790. 


\section{Referências bibliográficas}

\author{
ARAỨJO, Luís Antônio Silva. Em \\ nome do rei e dos negócios: direitos \\ e tributos régios nas minas \\ setecentistas (1730-1789). 2008. \\ Tese (Doutorado em História) - \\ Instituto de Ciências Humanas e \\ Filosofia, Universidade Federal \\ Fluminense, Niterói.
}

\section{ARQUIVO DO ESTADO} DE SÃO PAULO. Documentos Interessantes para a História e Costumes de São Paulo. São Paulo: Duprat e Comp., 1924. v. 45.

BONNEY, Richard. Les théories des finances publiques à l'époque moderne. In: BONNEY, Richard (Org.). Systèmes économiques et finances publiques. Paris: Presses Universitaires de France, 1996a. p. 153-223. (Les origines de l'État Moderne en Europe, XIII'-XVIII ${ }^{\mathrm{e}}$ siècle).

BONNEY, Richard. Le XVIIIe siècle. II. La lute pour le statut de grande puissance et la fin de l'ancien régime fiscal. In: BONNEY, Richard (Org.). Systèmes économiques et finances publiques. Paris: Presses Universitaires de France, 1996b. p. 315-395. (Les origines de l'État Moderne en Europe, XIII ${ }^{{ }^{-}}$ XVIII ${ }^{\mathrm{e}}$ siècle).
CARDOSO, José Luís. A influência de Adam Smith no pensamento económico português (1776-1811/12). In: CARDOSO, José Luís (Org.). Contribuições para a bistória do pensamento económico em Portugal. Lisboa: Dom Quixote, 1988. (Universidade Moderna, 84). p. $85-110$.

\section{CARDOSO, José Luís. O}

pensamento econômico em Portugal nos finais do século XVIII, 1780-1808. Lisboa: Estampa, 1989.

CARDOSO, José Luís. Nas malhas do Império: a economia política e a política colonial de D. Rodrigo de Souza Coutinho. In: CARDOSO, José Luís (Org.). A economia politica e os dilemas do Império luso-brasileiro (1790-1822). Lisboa: Comissão Nacional para as Comemorações dos Descobrimentos Portugueses, 2001. p. 63-110.

CARNAXIDE, Visconde de. $O$ Brasil na administracão pombalina (Economia e política externa). 2. ed. São Paulo: Nacional; Brasília: INL, 1979. (Brasiliana, v. 192).

CARRARA, Angelo Alves. Receitas e despesas da Real Fazenda no Brasil: século XVII. Juiz de Fora: Ed. UFJF, 2009a.
CARRARA, Angelo Alves. Receitas e despesas da Real Fazenda no Brasil: século XVIII. Juiz de Fora: Ed. UFJF, 2009b.

COSTA, Wilma Peres. Do domínio à nação: os impasses da fiscalidade no processo de Independência. In: JANCSÓ, István (Org.). Brasil: formação do Estado e da nação. São Paulo: Hucitec, 2003. p. 143-193.

CUNHA, Luís da. Testamento político; ou, carta escrita pelo grande D. Luiz da Cunha ao Senhor Rei D. José I antes do seu governo... São Paulo: Alfa-Ômega, 1976. (Testemunhas da História, 1).

ELLIS, Myriam. O monopólio do sal no estado do Brasil (1631-1801). São Paulo: Faculdade de Filosofia, Ciências e Letras, Universidade de São Paulo, 1955.

FALCON, Francisco José

Calazans. A época Pombalina: Política Econômica e Monarquia Ilustrada. 2. ed. São Paulo: Ática, 1993.

FIGUEIREDO, Luciano Raposo de Almeida. Derrama e política fiscal ilustrada. Revista do Arquivo Público Mineiro, Belo Horizonte, v. 41, p. 5-20, 2005.
FOURNIER DE FLAIX, E. La réforme de l'impôt en France. v. 1: Les théories fiscales et les impôts en France et en Europe aux XVII ${ }^{e}$ et XVIII ${ }^{e}$ siècles. Paris: Guillaumin \& Cie./Pedone-Lauriel, 1885. Reimpressão (Genève: Mégariotis Reprints, 1979).

GODINHO, Vitorino Magalhães. Finanças públicas e estrutura do Estado. In: SERRÃO, Joel (Org.). Dicionário de História de Portugal. Porto: Figueirinhas, 1992. v. 1 , p. 20-40.

GODOY, José Eduardo Pimentel de; MEDEIROS, Tarcízio Dinoá. Tributos, obrigações e penalidades pecuniárias de Portugal antigo. Brasília: ESAF, 1983.

GUÉRY, Alain. Les finances de la monarchie française sous l'Ancien Régime. Annales ESC, Paris, v. 33, n. 2, p. 216-239, 1978.

HESPANHA, António Manuel. Os poderes do centro: a fazenda. In: MATTOSO, José (Org.).

História de Portugal. Lisboa: Estampa, 1993. v. 4: o Antigo Regime (1620-1807), p. 214-236. 
LIMA, Manuel de Oliveira. Formação bistórica da nacionalidade brasileira. 3. ed. São Paulo: Publifolha; Rio de Janeiro: Topbooks, 2000.

LYRA, Maria de Lourdes Viana. $A$ utopia do poderoso Império. Portugal e Brasil: bastidores da política (17981822). Rio de Janeiro: Sette Letras, 1994.

MARICHAL, Carlos. La bancarrota del virreinato: Nueva España y las finanzas del Imperio español, 1780-1810. México, DF: Colégio de México; Fondo de Cultura Económica; Fideicomiso Historia de las Américas, 1999.

MAXWELL, Kenneth. A devassa da devassa. Inconfidência Mineira: Brasil e Portugal, 1750-1808. Rio de Janeiro: Paz e Terra, 1977.

MAXWELL, Kenneth. A geração de 1790 e a idéia do império luso-brasileiro. In: MAXWELL, Kenneth. Chocolate, piratas e outros malandros. São Paulo: Paz e Terra, 1999.

MORGAN, Edmund S. Colonial Ideas of Parliamentary Power 1764-1766. The William and Mary Quarterly, 3. ser., v. 5, n. 3, p. 311-341, 1948.

NOVAIS, Fernando A. Portugal e Brasil na crise do Antigo Sistema Colonial (1777-1808). 6. ed. Hucitec: São Paulo, 1995.
O'PHELAN, Scarlett. Las reformas fiscales borbónicas y su impacto en la sociedad colonial del Bajo y el Alto Peru. In: JACOBSEN, Nils; PUHLE, Hans-Jürgen (Eds.). The Economies of Mexico and Peru during the Late Colonial Period, 1760-1810. Berlin: Colloquium Verlag, 1986. p. 340356. (Bibliotheca Ibero-

Americana, v. 34).

PEDREIRA, Jorge; COSTA, Fernando Dores. D. João VI: um príncipe entre dois continentes. São Paulo: Companhia das Letras, 2008.

RENGER, Friedrich. O quinto do ouro no regime tributário nas Minas Gerais. Revista do Arquivo Público Mineiro, Belo Horizonte, v. 42, n. 2, p. 90-105, 2006.

SANTOS, Nívia Pombo Cirne dos. Dom Rodrigo de Sousa Coutinho: Pensamento e ação políticoadministrativa no Império Português (1778-1812). 2006. Dissertação (Mestrado em História) - Instituto de Ciências Humanas e Filosofia, Universidade Federal Fluminense, Niterói.

SERRÃO, José Vicente. O pensamento agrário setecentista (pré-“fisiocrático"): diagnósticos e soluções propostas. In: CARDOSO, José Luís (Org.). Contribuicōes para a história do pensamento económico em Portugal. Lisboa: Dom Quixote, 1988. (Universidade Moderna, 84). p. 23-50.
SILVA, Andrée Mansuy-Diniz (Org.). D. Rodrigo de Souza Coutinho. Textos políticos, económicos e financeiros (1783-1811). Lisboa: Banco de Portugal, 1993. 2 v. (Coleção Clássicos do Pensamento Econômico Português, 7).

SILVA, Andrée Mansuy-Diniz. Portrait d'un homme d'État: D. Rodrigo de Souza Coutinho, Comte de Linhares, 1755-

1812. Paris: Fundação Calouste Gulbekian, 2002-2006. 2v.

SILVA, Álvaro Ferreira da. Finanças públicas. In: LAINS, Pedro; SILVA, Álvaro Ferreira da (Orgs.). História Económica de Portugal 1700-2000. Lisboa: Imprensa de Ciências Sociais, 2005. v. 1: o século XVIII. p. 237-261.

SILVA, Ana Rosa Cloclet da. Inventando a nação: intelectuais ilustrados e estadistas lusobrasileiros na crise do Antigo Regime português, 1750-1822. São Paulo: Hucitec, 2006.

SMITH, Adam. Inquérito sobre a natureza e as causas da riqueza das nações. Lisboa: Fundação Calouste Gulbenkian, 1983. v. 2.

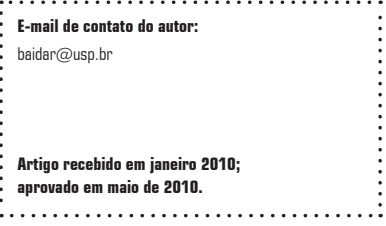

